Periodica Polytechnica Chemical Engineering, 65(3), pp. 416-423, 2021

\title{
Cave Air Analysis with Gas Chromatography Mass Spectrometry
}

\author{
Gyula Nyerges, Dénes Szieberth¹, Judit Mátyási¹,2, József Balla² \\ 1 Department of Inorganic and Analytical Chemistry, Faculty of Chemical Technology and Biotechnology, Budapest University of \\ Technology and Economics, H-1111 Budapest, 4 Szt. Gellért tér, Hungary \\ 2 B\&B Analytics Ltd., H-2030 Érd, 60 Terasz u., Hungary \\ *Corresponding author, e-mail: nyerges.gyula@vbk.bme.hu
}

Received: 14 January 2021, Accepted: 09 March 2021, Published online: 19 May 2021

\begin{abstract}
Gas chromatography (GC) is a frequently used analytical method for the determination of permanent and organic air components. The analysis usually needs two different columns in practice. The molecular sieve stationary phase can separate oxygen, nitrogen and carbon monoxide, but irreversibly adsorbs carbon dioxide and water. Porapak type columns are applicable for the measurement of carbon dioxide, however oxygen, argon, nitrogen and carbon monoxide are co-eluted. Usually these two types of columns are used in parallel for the determination. Carboxen stationary phase can separate carbon monoxide and carbon dioxide, but argon, oxygen and nitrogen are co-eluted. Thermal conductivity detector (TCD) and flame ionization detector (FID) are used commonly together for the determination of the separated components. TCD is applied for permanent gas analysis whereas FID - combined with a methanizer - is used for the detection of carbon monoxide, carbon dioxide and light hydrocarbons. Mass spectrometer (MS) is also a potential detector, because the properly chosen fragment ions can increase the selectivity.

We developed a method for the determination of air components, using only one column and one detector. This method is suitable for the measurements by combining the advantages of the carboxen column with mass spectrometry. The validation parameters of the method were in the acceptable interval, so this method is able to determine the air components. The application of this technique to the analysis of cave air provided valuable information to the exploration of the Molnár János cave system.
\end{abstract}

\section{Keywords}

gas chromatography mass spectrometry, cave air analysis, carboxen column, single column separation

\section{Introduction}

Atmospheric pressure gas sampling could be carried out by forced flow sampling, or by passive sampling (diffusion sampling). The forced flow is usually used with freezing type, absorption or adsorption type enrichments or volumetric sampling solutions. Volumetric gas sampling is possible, if the amount of the analyte concentration is more than the limit of detection and the boiling point of the monitored components is under $150{ }^{\circ} \mathrm{C}$. In this case, gas sampler tubes $[1,2]$, canisters $[1,3]$ and air sampling bags can be used [1, 3-5]. Polyethylene-terephthalate bottles and Giggenbach bottles [6] are also suitable for collecting gas samples. The storage conditions of the samples are very important. They must be under pressure and in order to protect them from the air, a closing liquid must be used. For this purpose, a saturated $\mathrm{CaCl}_{2}$ or saturated $\mathrm{Na}_{2} \mathrm{SO}_{4}$ solution is used [1].
The permanent gas analysis needs two different stationary phase for the separation among standard conditions [4, 7]. Cryogen chromatography is an option [4, 8]. Hydrogen, oxygen, nitrogen, carbon monoxide, carbon dioxide and light hydrocarbons can be separated on a Porapak Q column. First, the column must be cooled down to $-65{ }^{\circ} \mathrm{C}$ and then heated up to $200{ }^{\circ} \mathrm{C}$. The application of this very low temperature is difficult, so in the daily practice two column systems are used [9]. Previously packed columns were used for permanent gas analysis, but today capillary PLOT columns are widely spread. Capillary columns have better resolution and efficiency, and the separation is much faster [5]. These columns have a wider temperature tolerance and the stationary phase is more stable, which means less bleeding and with a lower background they have lower detection and quantitation limits [10]. 
The molecular sieve stationary phase is able to separate most of the permanent gases. However carbon dioxide, water vapor and heavy hydrocarbons adsorb irreversible at room temperature on the stationary phase. These components deactivate the zeolite $[1,4,8]$ and the efficiency of the separation gets worse [11]. The column must be regenerated [1]. Styrene-divinylbenzene (Porapak type column) is used for carbon dioxide and light hydrocarbons analysis $[1,2]$. The other components of the air cannot be separated from each other. Only one peak appears in the case of air, which contains argon, oxygen, nitrogen and carbon dioxide too $[4,5]$. Carboxen column is applicable to determine air components, but argon, oxygen and nitrogen have worse resolution than on the molecular sieve stationary phase $[1,4]$. The measurements were usually carried out at low column temperature $\left(20-55^{\circ} \mathrm{C}\right)$ under isothermal conditions $[2,7]$. Sometimes the isotherm temperature is higher $\left(70{ }^{\circ} \mathrm{C}\right)$ [11] or the applied temperature program has a heated phase at the end [9].

The well-chosen detector is very important. The thermal conductivity detector is universal and able to detect permanent gases [1]. Because it is also cheap, and its construction is simple and easy to use, this detector is widely used in the practice [10]. It has a wide linear range and it is not destructive [1]. But because of its big dead volume, it is not suitable for capillary columns and is less sensitive [1, 10, 12]. The flame ionization detector cannot measure nitrogen, oxygen, neither noble gases $[1,5,12]$, but with a methanizer unit, it is able to detect carbon monoxide and carbon dioxide [4, 13-15]. It has a very wide linear range and good sensitivity $[1,12]$, but it is a destructive detector, so other detectors cannot be combined with it $[1,2]$. The helium-ionization detector is able to ionize all the organic and inorganic components, but it is very sensitive and its impurities can give noise, so it has to be very pure. The efficient ionization makes this detector much more sensitive than the others. The mass spectrometer (MS) is universal and selective too [1]. It provides information about the quality and quantity of the analytical sample. The limit of detection is very low which makes it able to analyse minor components $[1,5,12]$. It cannot be efficiently used with a wide bore capillary column or packed column, because of the high amount of the eluent [1]. By MS we can make a total ion chromatogram (TIC) and we can use selective ion monitoring (SIM) to analyse only some fragments. Trace amount of carbon monoxide is detectable in a high amount of nitrogen by improving the sensitivity, if we are monitoring the 12 mass to charge $(\mathrm{m} / \mathrm{z})$ fragment of carbon monoxide instead of the total ion chromatogram [16].
For this study gas samples were collected from the Molnár János cave in Budapest near the Malom lake. $99 \%$ of the cave is submerged under water [17, 18]. With the exception of a large cave pool the cave can be accessed only through narrow fissures. Inside the cave there are gas filled chambers accessible only to divers, several hundred meters from the entrance (Fig. 1). Chambers filled with breathable air could provide refuge to divers in case of complications during the dive. Determining the composition of air in these chambers can also help finding connections to other cave systems or to the surface. Testing the ventilation of the cave at these locations by increasing the concentration of an inert gas then following the falloff can indicate communication with the surface or other gas-filled tunnels. The Molnár János cave is the youngest member of the Buda Thermal Karst system, providing the connection towards the other (already interconnected) caves are high priority both for cave explorers and for geologists.

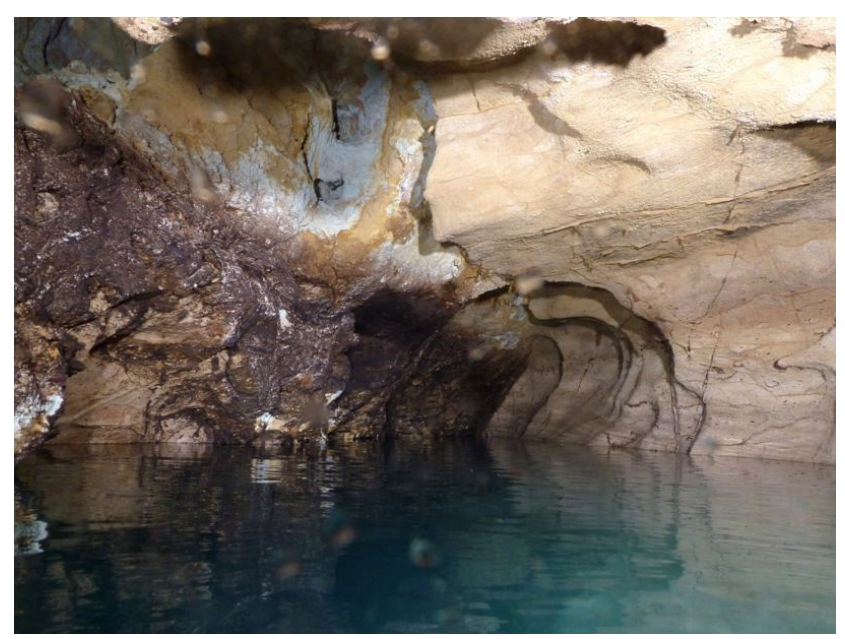

(a)

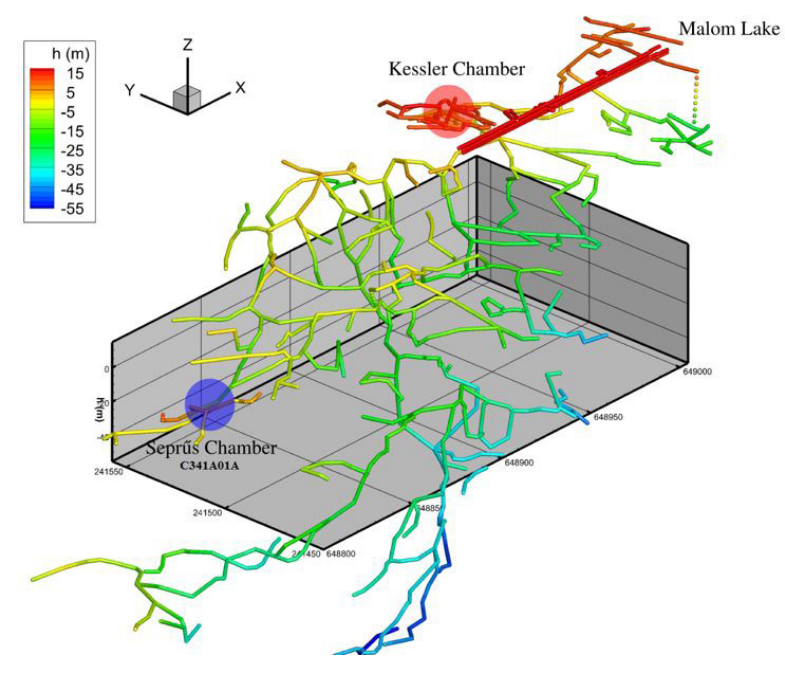

(b)

Fig. 1 "Seprűs" chamber in the Molnár János cave 


\section{Materials}

Standard gases like nitrogen (99.996\%), argon (99.995\%), oxygen (99.5\%), carbon dioxide (99.5\%) and helium (99.996 \%) were purchased from Linde. Formic acid and sulphuric acid for carbon monoxide standard were from Merck. Natural gas was used as methane standard.

\section{Sampling and preparation}

The air samples were collected by the divers. First, we used gas sampling tubes made of glass, which were stored under pressure with saturated $\mathrm{Na}_{2} \mathrm{SO}_{4}$ solution. In some cases, these tubes have broken in the narrow passages of the cave. Therefore, we tried PET soda bottles for air sampling. The bottles were filled with water on the site of the sampling, then lifted $\sim 1.5 \mathrm{~m}$ above the water surface with the help of a telescopic rod to avoid mixing with the diver's breathing gases, then inverted. After the water emptied the bottle was quickly lowered and closed. Sampling was repeated at different heights to check for stratification. The PET soda bottles were tested for leaking. The divers have taken parallel gas samples from the same cave chamber. One of the samples was measured on the sampling day, and the other was analysed later. The composition of the gas samples were the same after one week. According to this result we can state these bottles were appropriate for gas sampling and storing the samples for one week before measuring without any change in the composition. On the bottles we glued septa, thus with the help of a gastight syringe we could transfer the air sample into the gas chromatograph.

The calibration mixtures for the validation were made by static gas mixing. The concentration of the nitrogen $(\sim 60-80 \%)$ was out of the linear range, so we diluted the samples with helium. The other components were measured from the original sample. Thus we measured nitrogen and the other components with different temperature programs.

\section{Instrumentation}

For the analysis a Shimadzu GCMS-QP2010 was applied. The injections were carried out manually, with a gastight side hole syringe. The injected volume was $20 \mu \mathrm{L}$. Chromatograms were evaluated with GC/MS Solution software.

\section{GC-MS method}

The gas samples were analysed on a Carboxen 1010 PLOT $(30 \mathrm{~m} \times 0.32 \mathrm{~mm})$ capillary column. Helium was the carrier gas and the column flow was $4.48 \mathrm{~mL} \mathrm{~min}^{-1}$. The total flow was $117.4 \mathrm{~mL} \mathrm{~min}^{-1}$ and split ratios were for nitrogen and for the other components 150 and 25 respectively. The injector was held at $220^{\circ} \mathrm{C}$. Nitrogen was measured under isothermal condition at $35^{\circ} \mathrm{C}$. The other components were analysed with a column temperature program. The oven temperature was initially held at $35^{\circ} \mathrm{C}$ for 3 minutes, increased to $100{ }^{\circ} \mathrm{C}$ at $50{ }^{\circ} \mathrm{C} \mathrm{min}{ }^{-1}$ with the final temperature held for 4.7 minutes. The interface and the ion source temperature were set at $200{ }^{\circ} \mathrm{C}$ and the detector voltage was $1.10 \mathrm{kV}$. During the nitrogen determination the 28 $\mathrm{m} z^{-1}$ molecule ion was continuously monitored. Fragment 28 (nitrogen, carbon monoxide), 32 (oxygen), 40 (argon) was monitored from 1.50 to 3.00 minutes. Fragment 16 for methane was detected between 4.00 and 5.50 minutes. Carbon dioxide was measured from 6.25 to 9.00 minutes with its molecule ion 44 . The time windows of the monitored fragments are shown in Fig. 2.

\section{Validation}

Specificity was tested by static diluted gas mixtures. Nitrogen, oxygen, argon, carbon monoxide, carbon dioxide and methane were mixed in a headspace vial. Carbon monoxide was evolved in a headspace vial from the reaction of concentrated formic acid and sulphuric acid. We took a total ion chromatogram from the standard mix and tested it to make sure there are no peaks overlapped which has the same fragment. The linear range and calibration curve was created by 5 different concentration level of the validated components. The composition of the calibration gas mixtures are shown in Table 1. Limit of detection and limit of quantitation were calculated from the signal to noise level of the lowest calibration level of each component. The precision of the instrument was determined by measuring the same standard mix five times. The method precision was measured by two different gas mixtures. Oxygen, argon and carbon dioxide were in known quantity in one headspace vial and nitrogen was in helium in another vial. These samples were measured

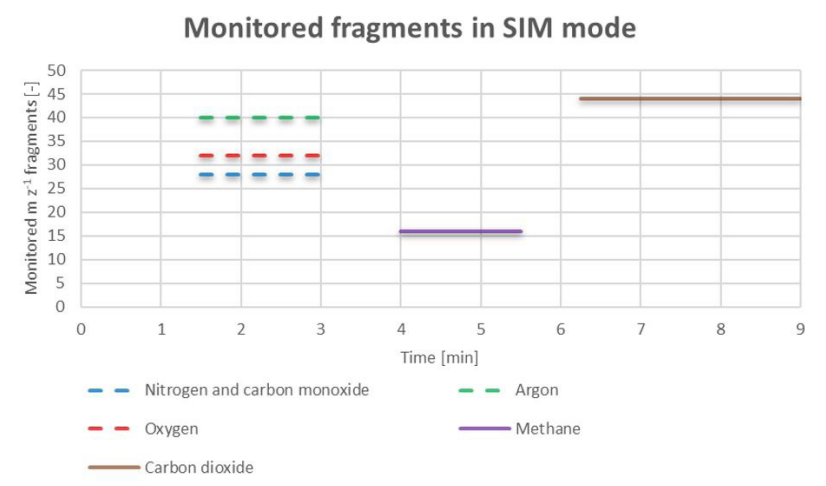

Fig. 2 The time windows of the selective ion monitoring measurements 
Table 1 The composition of the calibration mixtures

\begin{tabular}{|c|c|c|c|c|c|c|c|c|c|c|}
\hline \multicolumn{2}{|c|}{ Carbon dioxide } & \multicolumn{2}{|c|}{ Oxygen } & \multicolumn{2}{|c|}{ Argon } & \multicolumn{2}{|c|}{ Nitrogen } & \multicolumn{2}{|c|}{ Helium } & \multirow{2}{*}{$V_{\text {total }}[\mathrm{mL}]$} \\
\hline$V[\mathrm{~mL}]$ & $\mathrm{V} / \mathrm{V} \%[\%]$ & $V[\mathrm{~mL}]$ & $\mathrm{V} / \mathrm{V} \%[\%]$ & $V[\mathrm{~mL}]$ & $\mathrm{V} / \mathrm{V} \%[\%]$ & $V[\mathrm{~mL}]$ & $\mathrm{V} / \mathrm{V} \%[\%]$ & $V[\mathrm{~mL}]$ & $\mathrm{V} / \mathrm{V} \%[\%]$ & \\
\hline 5.5 & 19.8 & 1.0 & 3.6 & 0.025 & 0.1 & 21.3 & 76.6 & - & - & 27.8 \\
\hline 3.5 & 13.0 & 2.0 & 7.4 & 0.1 & 0.4 & 21.3 & 79.2 & - & - & 26.9 \\
\hline 2.0 & 7.1 & 4.5 & 16.0 & 0.4 & 1.4 & 21.3 & 75.5 & - & - & 28.2 \\
\hline 0.6 & 2.0 & 7.5 & 24.8 & 0.9 & 3.0 & 21.3 & 70.3 & - & - & 30.3 \\
\hline 0.2 & 0.6 & 10.0 & 30.3 & 1.5 & 4.6 & 21.3 & 64.6 & - & - & 33.0 \\
\hline- & - & - & - & - & - & 1.8 & 7.8 & 21.3 & 92.2 & 23.1 \\
\hline- & - & - & - & - & - & 3.0 & 12.4 & 21.3 & 87.6 & 24.3 \\
\hline- & - & - & - & - & - & 3.8 & 15.1 & 21.3 & 84.9 & 25.1 \\
\hline- & - & - & - & - & - & 4.5 & 17.4 & 21.3 & 82.6 & 25.8 \\
\hline- & - & - & - & - & - & 6.0 & 22.0 & 21.3 & 78.0 & 27.3 \\
\hline
\end{tabular}

three times. A known amount of the standard gases were spiked to each sample and we determined the recovery for every component. These results are characterizing the accuracy of the method. Robustness of the method was investigated with the change of chromatographic parameters. The oven temperature was increased from $35^{\circ} \mathrm{C}$ to $36^{\circ} \mathrm{C}$, linear velocity from $4.48 \mathrm{~mL} \mathrm{~min}^{-1}$ to $4.58 \mathrm{~mL} \mathrm{~min}^{-1}$ and injector temperature was decreased from $210^{\circ} \mathrm{C}$ to $200^{\circ} \mathrm{C}$.

\section{Results and discussion}

\subsection{Validation}

On the column carbon monoxide, methane and carbon dioxide are separated, but nitrogen, oxygen and argon are co-eluted. The total ion chromatogram is shown in Fig. 3. Using selective ion monitoring, the different ions of these analytes let us to determine the concentration of these components. The chosen fragments overlaid chromatogram is shown in Fig. 4. Expecting of the presence of hydrogen sulphide and water in the cave air, we used an extended temperature program to determine the retention time of these compounds as well. The retention times of the detected components are shown in Table 2.

The calibration curve for each component was linear in the examined range, except nitrogen. We had to dilute the sample in helium. Fig. 5. shows the saturated curve and the chosen linear range for the measurements. The limit of detection and quantitation was calculated from the chromatogram. The software calculated signal-to-noise ratios for each components in every calibration mix. We calculated the limit of detection (LOD) and limit of quantitation (LOQ) from the signal-to-noise ratio (LOD and LOQ correspond to 3 and 10 times to noise level, respectively). The equation of the calibration curves and the LOD and LOQ values are in Table 3.
The precision of the instrument for retention times and composition were characterized with the relative standard deviation (RSD). The method precision was examined in the case of parallel measurements of cave air sample. The relative standard deviation for each component was less than $15 \%$, so the instrument and the method are precise.

The samples were spiked by known quantities of the analytes and the accuracy was characterized with the recovery (REC). For nitrogen these results were a bit high, but in an acceptable range.

Robustness for each components were determined by changing a chromatographic parameter and calculating the relative standard deviation. The RSD showed the effect of each change in parameters for the qualitative analysis. The septum of the calibration mixes were pierced many times, which caused leakage and in time the RSD increased, but it was still in the acceptable interval. When we analyse a cave air sample, it only needs 3 injections, but in this case the sample was measured 12 times, so in case of real samples we do not have significant errors.

The expectations and the results of the validation are shown in Table 4.

\subsection{Cave air analysis}

The validated method was used to determine the composition of one of the air pockets of the cave system. This small chamber is located in the "Seprüs" branch at the northwestern end of the explored passages, above C35 line marking. This part of the cave is the closest known point to the Jánoshegyi cave, so continuation of the passages is sought actively in this direction, making the information gained from the gas analysis very important. The results for this measurement are shown in Table 5. The gas content of the chamber is significantly different from the surface air composition, so 


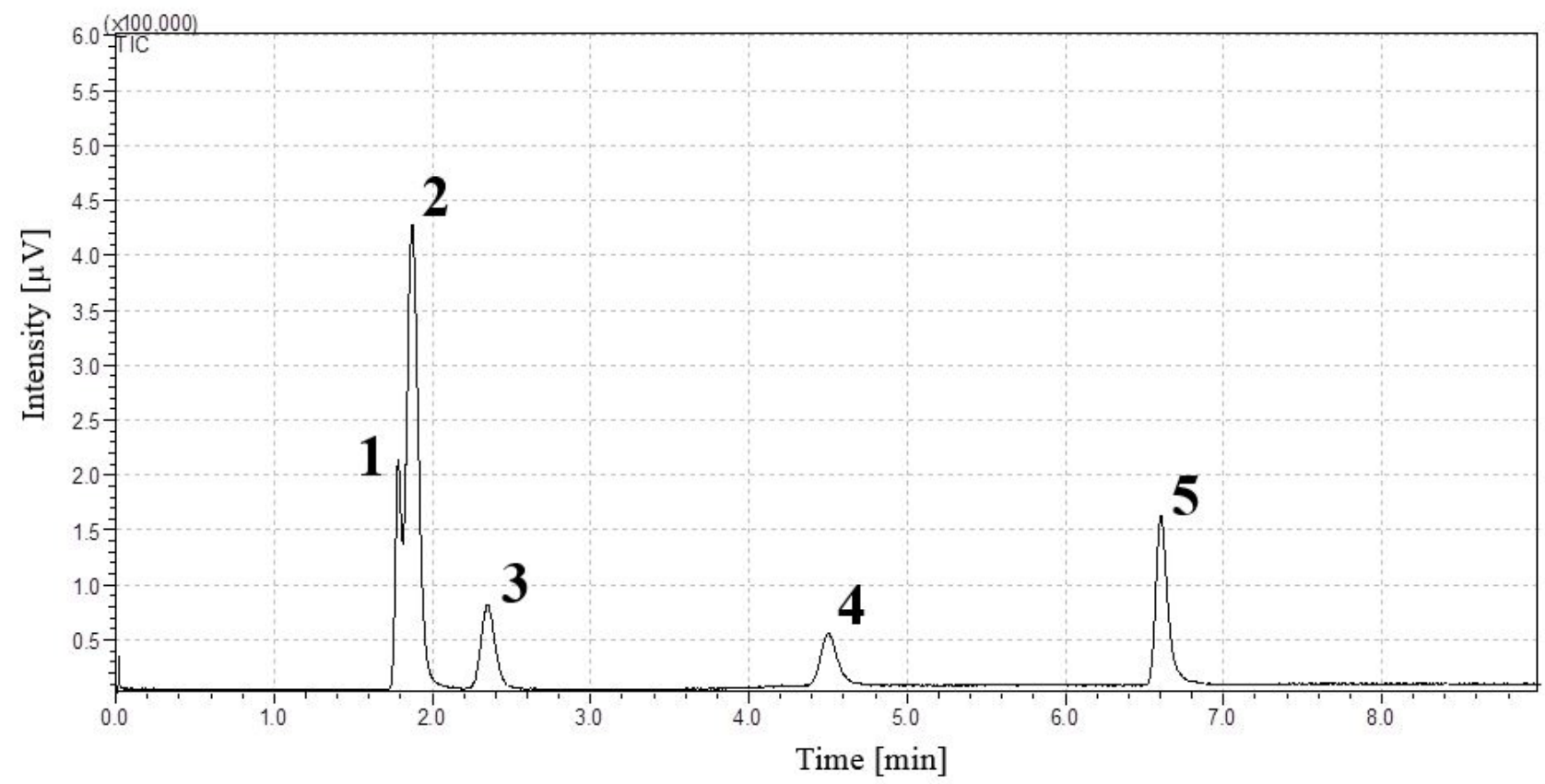

Fig. 3 The total ion chromatogram of the gas mixture $(1=$ argon and oxygen, $2=$ nitrogen, $3=$ carbon monoxide, $4=$ methane, $5=$ carbon dioxide $)$

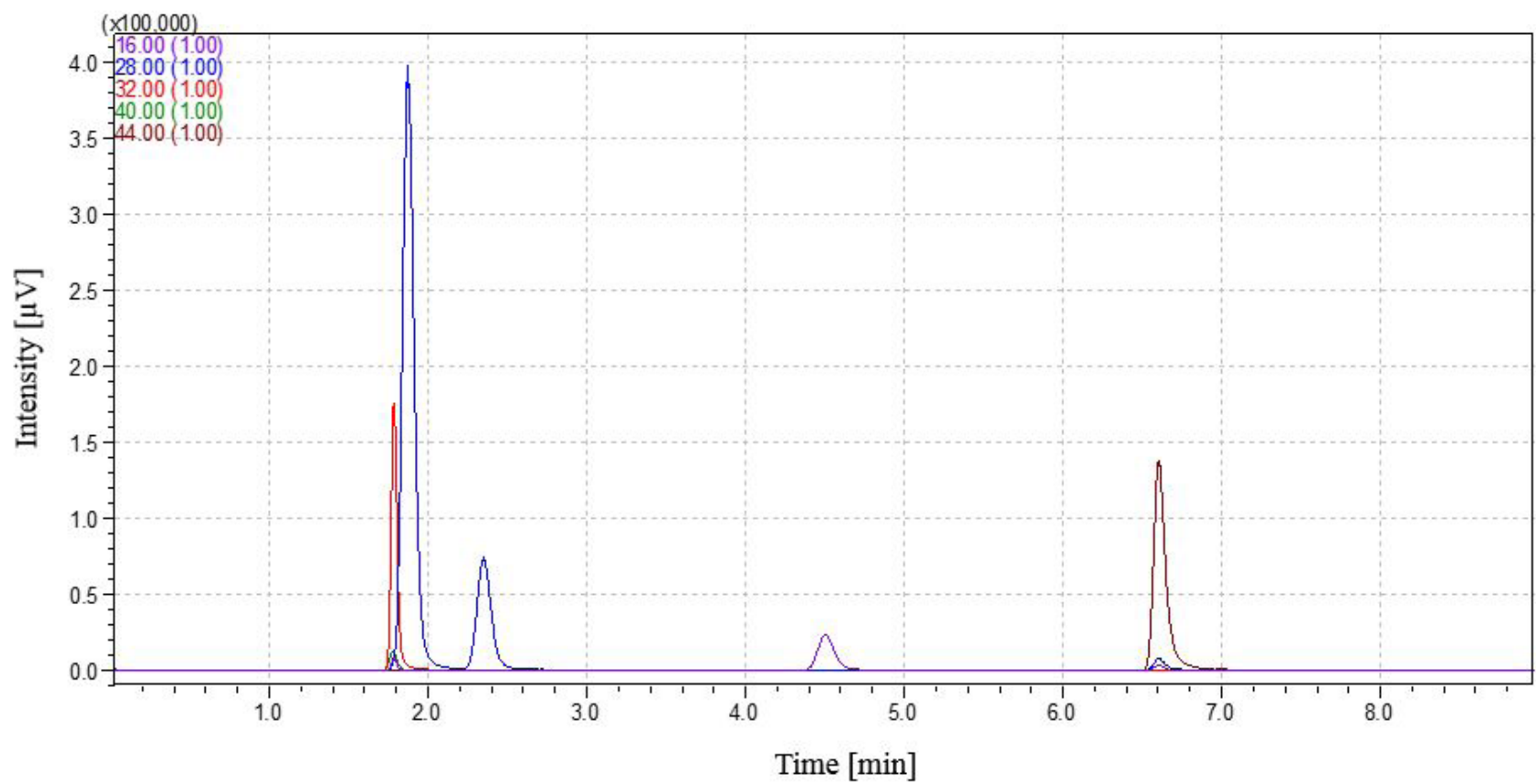

Fig. 4 The overlaid chromatogram of the chosen fragments

probably only insignificant ventilation is present towards the surface, although the pressure above the water is the same as the atmospheric pressure [19]. The carbon dioxide level is very high and the oxygen level is very low, so the divers cannot use this air pocket as a refuge. The obtained values are somewhat surprising, since the divers passing below the chamber use a $32 \% \mathrm{O}_{2}$ mix, and the released bubbles should elevate the oxygen level in the gas pocket.
To further test the ventilation of the "Seprüs" chamber, the concentration of argon was increased by releasing $\sim 0.5 \mathrm{Nm}^{3}$ of argon from a 51100 bar cylinder into the air space in about 5 minutes through a usual dive cylinder valve ( $\sim 2 \mathrm{~mm}$ bore). The high speed of the release and additional fanning with fin blades provided for the mixing, however the irregular shape of the top of the chamber made the perfect mixing impossible. The initial concentration 
Table 2 The retention times and the monitored fragments of the possible cave air components

\begin{tabular}{lcc}
\hline Component & Retention time [min] & Analysed fragment \\
\hline Argon & 1.945 & 40 \\
Oxygen & 1.957 & 32 \\
Nitrogen & 2.055 & 28 \\
Carbon monoxide & 2.597 & 28 \\
Methane & 4.677 & 16 \\
Carbon dioxide & 6.987 & 44 \\
Water & 10.099 & 18 \\
Hydrogen sulphide & 20.907 & 34 \\
\hline
\end{tabular}

Linear range of nitrogen

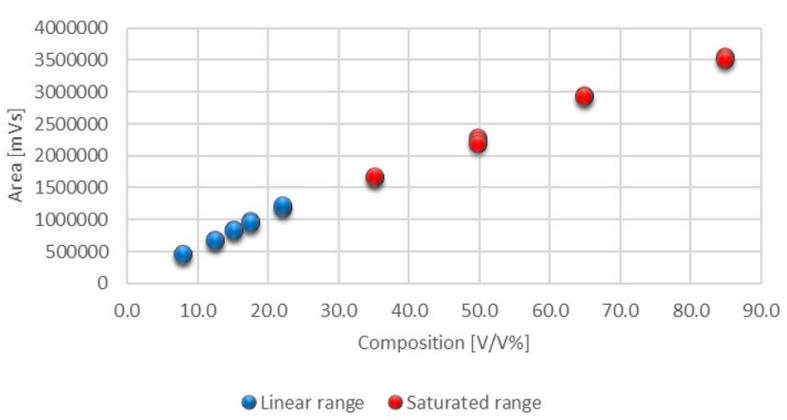

Fig. 5 The linear range of nitrogen

Table 3 The calibration equations and the LOD and LOQ values of each component

\begin{tabular}{cccc}
\hline & Calibration equation & LOD [V/V\%] & LOQ [V/V\%] \\
\hline $\mathrm{N}_{2}$ & $A_{\mathrm{N}_{2}}=55202 \times(\mathrm{V} / \mathrm{V} \%)_{\mathrm{N}_{2}}$ & 0.07 & 0.2 \\
$\mathrm{O}_{2}$ & $A_{\mathrm{O}_{2}}=113564 \times(\mathrm{V} / \mathrm{V} \%)_{\mathrm{O}_{2}}$ & 0.004 & 0.01 \\
$\mathrm{Ar}$ & $A_{\mathrm{Ar}}=202071 \times(\mathrm{V} / \mathrm{V} \%)_{\mathrm{Ar}}$ & 0.001 & 0.01 \\
$\mathrm{CO}_{2}$ & $A_{\mathrm{CO}_{2}}=223025 \times(\mathrm{V} / \mathrm{V} \%)_{\mathrm{CO}_{2}}$ & 0.004 & 0.003 \\
\hline
\end{tabular}

of the argon gas in the "Seprüs" chamber was measured to be $\sim 2 \%$, that also allowed us to estimate the volume of the chamber as $50 \mathrm{~m}^{3}$. This result is somewhat surprising, since the visible, lower part of the chamber was only estimated to be about $10 \mathrm{~m}^{3}$. Air samples were taken at gradually increasing intervals in the next months to trace the decay of the argon peak. The argon content was compared to the daily lab air composition. The relative argon content is shown in Fig. 6. The red dot shows the argon concentration after releasing immediately. The fluctuation shown in the case of the samples taken in the first week are probably due to imperfect mixing in the gas space. The argon concentration decreased to the original level only after 8 months. This let us conclude that the air pocket is connected to other chambers only through narrow fissures, allowing the equalization of the concentration only by slow diffusion.
Table 4 The results of the validation

\begin{tabular}{|c|c|c|c|c|}
\hline \multicolumn{2}{|c|}{ Performance characteristics } & Expec & tations & Results \\
\hline \multicolumn{2}{|l|}{ Calibration } & $\mathrm{R}^{2} \geq$ & 0.95 & $\mathrm{R}^{2} \geq 0.99$ \\
\hline \multicolumn{2}{|l|}{ LOD } & LOD & $0.1 \%$ & $\mathrm{LOD} \leq 0.07 \%$ \\
\hline \multicolumn{2}{|l|}{ LOQ } & LOQ & $0.5 \%$ & $\mathrm{LOQ} \leq 0.2 \%$ \\
\hline \multirow{2}{*}{$\begin{array}{l}\text { Precision } \\
\text { of the } \\
\text { instrument }\end{array}$} & Retention time & RSD & $<2 \%$ & $\mathrm{RSD}<0.2 \%$ \\
\hline & Composition & $\mathrm{RSD}$ & $<10 \%$ & $\mathrm{RSD}<6 \%$ \\
\hline \multicolumn{2}{|c|}{ Precision of the method } & RSD & $<15 \%$ & $\mathrm{RSD}<3 \%$ \\
\hline \multicolumn{2}{|c|}{ Accuracy/Recovery } & $\begin{array}{r}75 \%< \\
12\end{array}$ & $\begin{array}{l}\mathrm{REC}< \\
5 \%\end{array}$ & $\begin{array}{c}81 \%<\mathrm{REC}< \\
117 \%\end{array}$ \\
\hline \multicolumn{2}{|l|}{ Robustness } & $\mathrm{RSD}$ & $<15 \%$ & $\mathrm{RSD}<13 \%$ \\
\hline \multicolumn{5}{|c|}{ Table 5 The composition of cave air } \\
\hline & $\mathrm{O}_{2}$ content & $\mathrm{N}_{2}$ content & Ar content & $\mathrm{CO}_{2}$ content \\
\hline $\begin{array}{l}\text { Sample } \\
\text { composition } \\
{[\mathrm{V} / \mathrm{V} \%]}\end{array}$ & 10.1 & 79.5 & 0.9 & 4.5 \\
\hline
\end{tabular}

\section{Ventilation of argon in a cave chamber}

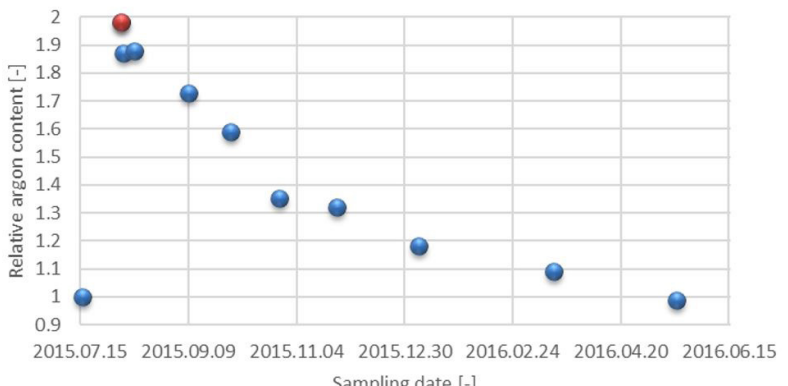

Fig. 6 The decrease of argon content in the cave (red - date of argon emission)

\section{Conclusion}

We have developed a gas chromatographic method for the determination of cave air composition. This method combines the selectivity of the mass spectrometer with the good separation conditions of the Carboxen type column and let us to determine the air composition using one column and one detector instead of applying two parallel columns and/or two different detectors, which are widely used for permanent gas analysis.

The results of the validation are sufficient to our expectations. The poor selectivity of the column was compensated with the mass spectrometer detector. The selective ion monitoring mode insured the selective detection 
of the compounds and resulted great sensitivity and low LOD and LOQ values. For the nitrogen measurements we diluted the sample in helium. The relationship between analyte signals and analyte concentration was linear in the measured range for all gas components. The accuracy, robustness, precision of the method and the apparatus were in the acceptance interval.

This method was used for the analysis of the cave air samples from the Molnár János cave. The samples were taken into PET soda bottles, which make sampling easier. The PET soda bottles were tested for leaking. According to these measurements these bottles are suitable for gas sampling and to be stored for one week before measuring without any change in the composition, providing a cheap alternative to glass or stainless steel samplers.

We have determined the air composition of a chamber. We have measured relative high carbon dioxide content and low oxygen concentration, which means, this pocket is not useable as a refuge. We have monitored the ventilation one of the air pocket of the cave, called "Seprüs". Argon gas was released in the chamber in known volume. Due to the argon concentration after the releasing, we were able to calculate

\section{References}

[1] Balla, J. "A gázkromatográfia analitikai alkalmazásai" (Analytical Applications of Gas Chromatography), Edison House Kft., Budapest, Hungary, 2006. (in Hungarian)

[2] Bernaldo de Quirós, Y., González-Díaz, Ó., Saavedra, P., Arbelo, M., Sierra, E., Sacchini, S., Jepson, P. D., Mazzariol, S., Di Guardo G., Fernández, A. "Methodology for in situ gas sampling, transport and laboratory analysis of gases from stranded cetaceans", Scientific Reports, 1(1), Article number: 193, 2011.

https://doi.org/10.1038/srep00193

[3] Blase, R. C., Patrick, E. L., Mitchell, J. N., Libardoni, M. "Analysis of cave atmospheres by comprehensive two-dimensional gas chromatography $(\mathrm{GC} \times \mathrm{GC})$ with flame ionization detection (FID)", Analytical Chemistry Research, 3, pp. 54-62, 2015.

https://doi.org/10.1016/j.ancr.2014.09.002

[4] Luong, J., Gras, R., Cortes, H. J., Shellie, R. A. "Multidimensional gas chromatography for the characterization of permanent gases and light hydrocarbons in catalytic cracking process", Journal of Chromatography A, 1271(1), pp. 185-191, 2013.

https://doi.org/10.1016/j.chroma.2012.11.025

[5] Bai, L., Smuts, J., Walsh, P., Fan, H., Hildenbrand, Z., Wong, D., Wetz, D., Schug, K. A. "Permanent gas analysis using gas chromatography with vacuum ultraviolet detection", Journal of Chromatography A, 1388, pp. 244-250, 2015. https://doi.org/10.1016/j.chroma.2015.02.007

[6] Joseph, E. P., Fournier, N., Lindsay, J. M., Fischer, T. P. "Gas and water geochemistry of geothermal systems in Dominica, Lesser Antilles island arc", Journal of Volcanology and Geothermal Research, 206(1-2), pp. 1-14, 2011.

https://doi.org/10.1016/j.jvolgeores.2011.06.007 the volume of the air pocket. The decrease of the argon concentration to the original level took 8 months. It means, this chamber is not completely isolated, it is connected to other air pockets - maybe to the other caves of the Buda Thermal Karst - through narrow fissures. In the future we would continue our measurements, to confirm this possibility.

\section{Acknowledgements}

The authors thank for B\&B Analytics Ltd. (Érd, Hungary) for providing financial and technical support. In particular we would like to thank Attila Hosszú, József Spanyol and the Molnar Janos Cave Research Group to collect and provide us all of the gas samples from the Molnár János cave. The research reported in this paper and carried out at the Budapest University of Technology and Economics has been supported by the National Research Development and Innovation Fund (TKP2020 Institution Excellence Subprogram, Grant No. TKP2020 BME-IKA-VIZ) based on the charter of bolster issued by the National Research Development and Innovation Office under the auspices of the Ministry for Innovation and Technology.

[7] van Rensburg, M. J., Botha, A., Rohwer, E. "Analysis of trace amounts of carbon dioxide, oxygen and carbon monoxide in nitrogen using dual capillary columns and a pulsed discharge helium ionisation detector", Journal of Chromatography A, 1167(1), pp. 102-108, 2007.

https://doi.org/10.1016/j.chroma.2007.07.055

[8] Grob, R. L. "Chromatographic analysis of the environment", Marcel Dekker INC., New York, NY, USA, 1983.

[9] Nand, S., Sakkar, M. K. "One-step analysis of a mixture of permanent gases and light hydrocarbons by gas chromatography", Journal of Chromatography A, 89(1), pp. 73-75, 1974. https://doi.org/10.1016/S0021-9673(01)84160-1

[10] Zhou, Y. H., Wang, C. X., Firor, R., "Analysis of Permanent Gases and Methane with the Agilent 6820 Gas Chromatograph", Agilent Technologies, Inc., USA, 2003. [online] Available at: https:// www.agilent.com/cs/library/applications/5988-9260EN.pdf [Accessed: 12 May 2021]

[11] Trubyanov, M. M., Mochalov, G. M., Vorotyntsev, I. V., Vorotyntsev, A. V., Suvorov, S. S., Smirnov, K. Y., Vorotyntsev, V. M. "An improved back-flush-to-vent gas chromatographic method for determination of trace permanent gases and carbon dioxide in ultra-high purity ammonia", Journal of Chromatography A, 1447, pp. 129-134, 2016. https://doi.org/10.1016/j.chroma.2016.04.020

[12] Pokol, G., Gyurcsányi, R. E., Simon, A. Bezur, L., Horvai, G., Horváth, V., Dudás, K. M. "Analitikai kémia" (Analytical Chemistry), Typotex Kiadó, Budapest, Hungary, 2011. (in Hungarian) 
[13] Novelli, P. C. "CO in the atmosphere: measurement techniques and related issues", Chemosphere - Global Change Science, 1(1-3), pp. 115-126, 1999. https://doi.org/10.1016/S1465-9972(99)00013-6

[14] Kamiński, M., Kartanowicz, R., Jastrzębski, D., Kamiński, M. M. "Determination of carbon monoxide, methane and carbon dioxide in refinery hydrogen gases and air by gas chromatography", Journal of Chromatography A, 989(2), pp. 277-283, 2003. https://doi.org/10.1016/S0021-9673(03)00032-3

[15] Porter, K., Volman, D. H. "Flame Ionization Detection of Carbon Monoxide for Gas Chromatographic Analysis", Analytical Chemistry, 34(7), pp. 748-749, 1962. https://oi.org/10.1021/ac60187a009

[16] Aflalaye, A., Sternberg, R., Coscia, D., Raulin, F., Vidal-Madjar, C. "Gas chromatography of Titan's atmosphere VIII. Analysis of permanent gases with carbon molecular sieve packed capillary columns", Journal of Chromatography A, 761(1-2), pp. 195-203, 1997. https://doi.org/10.1016/S0021-9673(96)00806-0
[17] Kalinovits, S. "Molnár János-barlang" (Molnár János cave), In: Székely, K. (ed.) Magyarország fokozottan védett barlangjai (Highly Protected Caves of Hungary), Mezőgazda Kiadó, Budapest, Hungary, 2003, pp. 260-263. (in Hungarian)

[18] Bergmann, C., Leél-Őssy, S., Fehér, K., Fórizs, I. "Vízvizsgálatok a Molnár János-barlangban" (Water analyzes in the Molnár János Cave), Karsztfejlödés, 16, pp. 223-245, 2011. [online] Available at: http://epa.oszk.hu/03100/03192/00016/pdf/EPA03192_karsztfejlodes_2011_16_223-245.pdf [Accessed: 02 January 2021] (in Hungarian)

[19] Müllner, L., Hosszú, A., Storozynski, S., Zsoldos, P., Szieberth, D., Müllner-Lencsés, E., Virág, M., Nagy, G. "Molnár János-barlang, Kutatási jelentés" (Molnár János cave, Research report), [pdf] Budapest, Hungary, 2015. Available at: http://www.termeszetvedelem.hu/_user/browser/File/barlangkutat $\% \mathrm{C} 3 \% \mathrm{~A} 1 \mathrm{si} \% 20$ jelent\%C3\%A9sek/2015/mullner_laszlo_2015.pdf [Accessed: 02 January 2021] (in Hungarian) 